\title{
Arterial compliance and distensibility are modulated by body composition in both men and women but by insulin sensitivity only in women
}

\author{
E.J. Giltay ${ }^{1}$, J. Lambert ${ }^{2,3}$, J. M.H. Elbers ${ }^{1}$, L. J. G. Gooren ${ }^{1}$, H. Asscheman ${ }^{1}$, C. D. A. Stehouwer ${ }^{2,3}$ \\ ${ }^{1}$ Institute of Endocrinology, Reproduction and Metabolism, Hospital Vrije Universiteit, Amsterdam, The Netherlands \\ ${ }^{2}$ Department of Internal Medicine, Hospital Vrije Universiteit, Amsterdam, The Netherlands \\ ${ }^{3}$ Institute for Cardiovascular Research, Hospital Vrije Universiteit, Amsterdam, The Netherlands
}

Summary Large artery stiffening could contribute to the development of cardiovascular disease. The aim of this study was to investigate associations between arterial stiffness and diameter with insulin sensitivity and body composition in healthy men and women. In healthy, young $(<41$ years old $)$, non-obese $\left(\mathrm{BMI}<27 \mathrm{~kg} / \mathrm{m}^{2}\right)$ men $(n=17)$ and women $(n=17)$, we measured the arterial diameter, the distension, the distensibility coefficient and the compliance coefficient of the elastic common carotid and muscular femoral arteries with a non-invasive ultrasonographic method. We also assessed glucose uptake (by a euglycaemic hyperinsulinaemic clamp technique), total body fat and lean body mass (by bioelectrical impedance analysis) and abdominal subcutaneous and visceral fat area (by magnetic resonance imaging). In women, but not in men, the distension and distensibility and compliance coefficients of the femoral artery were negatively associated with insulin concen- trations $(\beta=-0.62, p=0.008 ; \beta=-0.65, p=0.005$ and $\beta=-0.59, p=0.01$, and positively with glucose uptake $(\beta=0.59, p=0.02 ; \beta=0.68, p=0.005$ and $\beta=0.54, p=0.04)$. Associations with glucose uptake were independent of the mean arterial pressure and body composition. In men and women, arterial compliance was positively associated with fat mass variables, which were mediated by a strong association between the femoral artery diameter and lean body mass $(\beta=0.80, p<0.001)$ and between the common carotid artery diameter and visceral fat area $(\beta=0.56, p=0.001)$. We found an independent association between insulin resistance and arterial stiffness, which was more pronounced in women than in men. [Diabetologia (1999) 42: 214-221]

Keywords Insulin sensitivity, carotid artery, femoral artery, distensibility coefficient, compliance coefficient, body composition.
Large artery stiffening, reflected by low distensibility and compliance, impairs the ability of the arterial system to cushion pulsatile pressure [1-3]. Arterial stiffening results in a higher pulse wave velocity and earlier wave reflections. This increases systolic and pulse pressure and consequently cardiac workload [2, 3].

Received: 8 May 1998 and in revised form: 18 August 1998

Corresponding author: C.D.A. Stehouwer, MD, Department of Internal Medicine, Hospital Vrije Universiteit, P.O. Box 7057, 1007 MB, Amsterdam, The Netherlands

Abbreviations: CC, Compliance coefficient; D, diameter; DC, distensibility coefficient; $\delta \mathrm{D}$, change in arterial diameter during the heart cycle; $\delta \mathrm{P}$, pulse pressure; LBM, lean body mass; MAP, mean arterial pressure.
Over time, arterial stiffening can contribute to the development of left ventricular hypertrophy, congestive heart failure and coronary heart disease [4-8]. These complications are especially common in insulin resistant states present in obese subjects $[9,10]$, in men $[11,12]$ or women [13] with increased fasting insulin concentrations, in prediabetic subjects [14], and in patients with Type II (non-insulin-dependent) diabetes mellitus [15-17]. Therefore, insulin resistance could be linked to arterial stiffening, either directly or indirectly. Indeed arterial stiffness is associated with fasting insulin concentrations [18-20], the latter being a reasonable, though imperfect, marker of insulin resistance among subjects with normal glucose tolerance [21]. There are some indications that sex modulates this association, since associations between ar- 
Table 1. Demographic, haemodynamic, metabolic, and body composition characteristics of the study group

\begin{tabular}{|c|c|c|c|c|c|}
\hline & $n$ & Men & $n$ & Women & $p$ \\
\hline $\begin{array}{l}\text { Age (years) } \\
\text { Smokers }(n)\end{array}$ & $\begin{array}{l}17 \\
17\end{array}$ & $\begin{array}{l}28 \pm 7 \\
10\end{array}$ & $\begin{array}{l}17 \\
17\end{array}$ & $\begin{array}{l}23 \pm 5 \\
11\end{array}$ & $\begin{array}{l}0.02 \\
0.72\end{array}$ \\
\hline $\begin{array}{l}\text { Femoral artery diameter }(\mathrm{mm}) \\
\text { Femoral artery DC }\left(10^{-3} \cdot \mathrm{kPa}^{-1}\right) \\
\text { Femoral artery CC }\left(\mathrm{mm}^{2} \cdot \mathrm{kPa}^{-1}\right) \\
\text { Carotid artery diameter }(\mathrm{mm}) \\
\text { Carotid artery DC }\left(10^{-3} \cdot \mathrm{kPa}^{-1}\right) \\
\text { Carotid artery CC }\left(\mathrm{mm}^{2} \cdot \mathrm{kPa}^{-1}\right) \\
\text { Mean arterial pressure }(\mathrm{mmHg})\end{array}$ & $\begin{array}{l}17 \\
17 \\
17 \\
17 \\
17 \\
17 \\
17\end{array}$ & $\begin{array}{l}7.6 \pm 1.1 \\
22.2 \pm 8.9 \\
0.93 \pm 0.27 \\
6.1 \pm 0.5 \\
28.0 \pm 7.8 \\
0.80 \pm 0.19 \\
87 \pm 9\end{array}$ & $\begin{array}{l}17 \\
17 \\
17 \\
17 \\
17 \\
17 \\
17\end{array}$ & $\begin{array}{l}6.5 \pm 0.7 \\
24.6 \pm 9.7 \\
0.80 \pm 0.25 \\
5.7 \pm 0.4 \\
29.0 \pm 4.6 \\
0.72 \pm 0.13 \\
80 \pm 5\end{array}$ & $\begin{array}{l}0.003 \\
0.46 \\
0.15 \\
0.005 \\
0.65 \\
0.18 \\
0.02\end{array}$ \\
\hline $\begin{array}{l}\text { Glucose }(\mathrm{mmol} / \mathrm{l}) \\
\text { Insulin }(\mathrm{pmol} / \mathrm{l}) \\
\text { Glucose uptake }\left(\mathrm{mg} \cdot \mathrm{kg} \mathrm{LBM}^{-1} \cdot \mathrm{min}^{-1}\right)\end{array}$ & $\begin{array}{l}17 \\
17 \\
15\end{array}$ & $\begin{array}{l}5.3 \pm 0.7 \\
39 \pm 14 \\
7.4 \pm 2.5\end{array}$ & $\begin{array}{l}17 \\
17 \\
15\end{array}$ & $\begin{array}{l}4.9 \pm 0.6 \\
51 \pm 26 \\
7.5 \pm 2.6\end{array}$ & $\begin{array}{l}0.11 \\
0.12 \\
0.89\end{array}$ \\
\hline $\begin{array}{l}\text { HDL-cholesterol }(\mathrm{mmol} / \mathrm{l}) \\
\text { Triglyceride }(\mathrm{mmol} / \mathrm{l}) \\
\text { Non-esterified fatty acids (mmol/l) }\end{array}$ & $\begin{array}{l}17 \\
17 \\
17\end{array}$ & $\begin{array}{l}1.04 \pm 0.18 \\
0.94 \pm 0.58 \\
0.65 \pm 0.33\end{array}$ & $\begin{array}{l}17 \\
17 \\
17\end{array}$ & $\begin{array}{l}1.26 \pm 0.34 \\
0.79 \pm 0.47 \\
0.67 \pm 0.25\end{array}$ & $\begin{array}{l}0.03 \\
0.38 \\
0.82\end{array}$ \\
\hline $\begin{array}{l}\text { Body mass index }\left(\mathrm{kg} / \mathrm{m}^{2}\right) \\
\text { Waist-to-hip ratio }(\mathrm{m} / \mathrm{m}) \\
\text { Lean body mass }(\mathrm{kg}) \\
\text { Total body fat }(\mathrm{kg}) \\
\text { Abdominal subcutaneous fat area }\left(\mathrm{cm}^{2}\right) \\
\text { Visceral fat area }\left(\mathrm{cm}^{2}\right)\end{array}$ & $\begin{array}{l}17 \\
15 \\
15 \\
15 \\
13 \\
13\end{array}$ & $\begin{array}{l}21.2 \pm 2.6 \\
0.83 \pm 0.04 \\
57.4 \pm 9.2 \\
10.4 \pm 3.3 \\
84 \pm 40 \\
41 \pm 15\end{array}$ & $\begin{array}{l}17 \\
15 \\
15 \\
15 \\
14 \\
14\end{array}$ & $\begin{array}{l}20.8 \pm 2.1 \\
0.80 \pm 0.04 \\
43.4 \pm 6.2 \\
16.0 \pm 5.4 \\
151 \pm 75 \\
37 \pm 14\end{array}$ & $\begin{array}{l}0.59 \\
0.053 \\
<0.001 \\
0.002 \\
0.009 \\
0.48\end{array}$ \\
\hline
\end{tabular}

Data are means \pm SD

terial stiffness variables and fasting insulin are stronger in women than in men [20].

Insulin resistance is also associated with several metabolic and haemodynamic disturbances, i.e. dyslipidaemia, visceral fat accumulation and hypertension [22]. Arterial stiffness has been shown to be positively associated with blood pressure [19, 23, 24], visceral fat accumulation [25] and plasma concentrations of triglycerides $[18,26]$ and non-esterified fatty acids [26] and negatively with plasma concentrations of HDL-cholesterol [19, 24]. By contrast, young obese subjects can have a decreased arterial stiffness compared to non-obese subjects [27]. It is not known, however, whether these associations are also present in healthy, young, non-obese subjects, since previous studies included middle-aged subjects $[18,20$, 23-26], obese subjects [18-20, 23-27], and patients with Type II diabetes [26]. Moreover, previous studies did not include all these measurements in one statistical model and used fasting insulin concentrations as an estimate of insulin sensitivity [18-20].

We therefore investigated the associations between arterial distensibility and compliance of the elastic common carotid and muscular femoral arteries and insulin sensitivity in healthy, young, nonobese men and women. We aimed particularly to examine whether this association was independent of the mean arterial pressure (MAP), lipid concentrations and body composition. Insulin sensitivity and fat distribution were assessed with the gold standard, i.e. the euglycaemic hyperinsulinaemic clamp [28] and magnetic resonance imaging technique respectively.

\section{Subjects and methods}

Subjects. Seventeen male and 17 female healthy, young $(0 \leq 40$ years old), white subjects participated in the study. Subjects with a BMI (weight/height ${ }^{2}$ ) greater than $26 \mathrm{~kg} / \mathrm{m}^{2}$ were excluded. All subjects were free of hypertension, diabetes mellitus and cardiovascular disease according to their medical history, physical examination, and laboratory tests. None reported taking medicine known to affect blood pressure, lipid metabolism or insulin sensitivity. We measured haemodynamic variables (arterial diameter $[\mathrm{D}]$, distension $[\delta \mathrm{D}]$, distensibility coefficient [DC], compliance coefficient [CC], and MAP), insulin sensitivity (fasting glucose and insulin concentrations and glucose uptake), plasma lipids and body composition (BMI, waist-to-hip ratio, lean body mass, total body fat, and abdominal subcutaneous and visceral fat area). For logistical reasons, some measurements were not obtained for all subjects (Table 1). Blood samples were obtained in the morning between 0930 and 1030 hours after an overnight fast, to measure plasma insulin (with a immunoradiometric assay; coefficient of variation intra-assay, $5 \%$, interassay, $7 \%$; Biosource Diagnostics, Fleurus, Belgium) and glucose (using standard laboratory methods). Enzymatic colorimetric methods were used to measure plasma concentrations of high-density lipoprotein (HDL) cholesterol after phosphotungstic acid/magnesium chloride precipitation, triglycerides (Boehringer Mannheim, Mannheim, Germany), and non-esterified fatty acids (Wako Chemicals, Richmond, USA). The investigation conformed with the principles outlined in the Declaration of Helsinki. Informed consent was obtained from all subjects and the study was approved by the ethics review board of the Hospital Vrije Universiteit.

Haemodynamic measurements. The DC, reflecting the intrinsic vascular wall elasticity, and the $\mathrm{CC}$, reflecting the buffering capacity of the vessel wall, can be reproducibly estimated with a noninvasive ultrasound system [29, 30]. All subjects refrained from smoking or consuming caffeine for at least $4 \mathrm{~h}$ before examination. All haemodynamic measurements were taken after 
at least $15 \mathrm{~min}$ of supine rest in a temperature-controlled, quiet room. The DC and the $\mathrm{CC}$ were calculated from the arterial diameter (D), the change in arterial diameter during the heart cycle $(\delta \mathrm{D})$ and pulse pressure $(\delta \mathrm{P})$ as follows: $\mathrm{DC}=(2 * \delta \mathrm{D}) /$ $(\mathrm{D} * \delta \mathrm{P})$ and $\mathrm{CC}=\left(\pi^{*} \delta \mathrm{D} * \mathrm{D}\right) /(2 * \delta \mathrm{P})[29,31,32]$. The withinsubjects coefficients of variation for DC and CC were $7.7 \%$ and $8.3 \%$ for the common cartoid artery and $17.0 \%$ and $15.2 \%$ for the femoral artery [30, 33]. All measurements were taken in the morning before 1100 hours in blinded fashion with respect to the other metabolic measurements by means of a vessel movement detector system (Wall Track System, Neurodata, Bilthoven, The Netherlands) consisting of an ultrasound imager (Ultramark IV, ATL, Bothell, USA) connected with a data registration and processing unit [29]. In short, a longitudinal section of the vessel was obtained in B-mode with a $7.5 \mathrm{MHz}$ transducer. Using the $\mathrm{M}$-mode, the vessel movement detector system repeatedly registered the vessel wall distension and diastolic diameter during a period of 5 to 6 seconds. The registrations were made $10 \mathrm{~mm}$ proximal of the right femoral artery bifurcation and the right carotid artery bifurcation. On the left arm, the MAP was measured directly, and systolic and diastolic blood pressures were calculated with an automatic oscillometric device (BP-8800, Colin, Hayashi Komaki City, Japan). The difference between the diastolic and systolic blood pressure $(\delta P)$ was calculated. The blood pressure was not assessed at the site of diameter measurements in the common carotid artery and femoral artery, but it has been shown that the brachial pressure provides a relatively good non-invasive approximation [34]. (In this group of subjects we also measured the brachial artery DC and CC but we have not presented the results on these measurements because the large coefficients of variation of these measurements precluded a meaningful analysis). Data of the measurement of the femoral artery, another muscular artery, provided information on the relations with muscular artery stiffness.

Body composition. The lean body mass (LBM) and the total body fat were estimated using bioelectrical impedance analysis (BIA 101/S, RJL Systems, Clinton Twp, Detroit, Mich., USA) [35]. In addition, body circumferences were measured in duplicate with a flexible plastic tape at the level of the abdomen (midway between the lower rib margin and the iliac crest) and the hip (over the greater trochanters), to calculate the waistto-hip ratio. Since regional distribution of adipose tissue, especially the amount of visceral fat, could be an important risk factor for non-insulin dependent diabetes and coronary heart disease [36, 37] and differs between the two sexes [37], we also assessed areas of abdominal subcutaneous and visceral fat depots using a magnetic resonance imaging technique [38]. Also, preferential accumulation of fat takes place in the two sexes: the visceral depot (android obesity) in men and the subcutaneous depots (gynecoid obesity) in women. Repeated measurements were obtained using the same magnetic resonance imager and scanning variables within a week of the haemodynamic measurements. An inversion recovery pulse sequence was used and appropriate scanning variables were chosen to obtain good image contrast between adipose and other tissues. Three transverse images were taken at the abdominal level: one at the anatomical marker (lower edge of the umbilicus), one above and one below this position (slice thickness: 10 or $12 \mathrm{~mm}$, dependent on the imager). The image-analysing computer program (developed by our Department of Biomedical Engineering) is based on a seed growing procedure. In short, after a seed point is placed in the abdominal subcutaneous or the visceral fat depot, this depot can be circumscribed by selection of a pixel intensity range. The intensity range is selected for each image separately according to the pixel intensity his- togram. The areas of the circumscribed abdominal subcutaneous and visceral fat depots were calculated by converting the number of pixels to $\mathrm{cm}^{2}$ and the average of the three abdominal images was taken. To reduce variability, all measurements were taken by one experienced observer. The intraobserver coefficients of variation were $2.3 \%$ for abdominal subcutaneous fat and $9.8 \%$ for visceral fat [38].

Euglycaemic hyperinsulinaemic clamp. Insulin sensitivity was measured within a week of the haemodynamic measurements using a euglycaemic hyperinsulinaemic clamp technique [28] which started in the morning between 0930 and 1030 hours after an overnight fast, on the same day of the blood sampling. Two intravenous catheters were placed in contralateral antecubital or antebrachial veins of each arm, one for blood withdrawal and the other for insulin and glucose infusion. The insulin solution for intravenous infusion was prepared by adding $0.5 \mathrm{ml}$ human insulin $(100 \mathrm{U} / \mathrm{ml}$; Velosulin, Novo Nordisk A/S, Bagsvaerd, Denmark) and $4.5 \mathrm{ml}$ human albumin $20 \%$ (Central Laboratory, Amsterdam, The Netherlands) to $45 \mathrm{ml}$ isotonic sodium chloride $0.9 \%$, to a final insulin concentration of $1 \mathrm{U} / \mathrm{ml}$. The insulin infusion rate, calculated per $\mathrm{kg} \mathrm{LBM}$, was $62.5 \mathrm{mU} \cdot \mathrm{kg} \mathrm{LBM}^{-1} \cdot \mathrm{h}^{-1}$. The clamp procedure was started $30 \mathrm{~min}$ after cannulation. After the start of the insulin infusion, arterialized blood glucose concentrations were measured every 5 min using a YSI Glucose Analyser (glucose oxidase method; Yellow Springs, Ohio, USA). The glucose $20 \%$ infusion rate was adjusted to maintain blood glucose concentration at the fasting level (i.e. mean blood glucose concentration $30 \mathrm{~min}$ before the start of the insulin infusion). Glucose uptake was calculated from the steady-state glucose infusion rate in the second hour and the LBM, i.e. M-value $(\mathrm{mg} \cdot \mathrm{kg}$ $\left.\mathrm{LBM}^{-1} \cdot \mathrm{min}^{-1}\right)$.

Statistical analysis. Data are given as means \pm SD. Variables with a skewed distribution (abdominal subcutaneous fat area and plasma triglyceride concentrations) were logarithmically transformed before analysis to normalize their distributions. To compare differences between men and women, Student's $t$-test and a linear regression model were used. We used a linear regression model with independent variables chosen on the basis of pathophysiological assumptions to analyse associations of haemodynamic measurements $(\mathrm{DC}, \mathrm{CC}, \delta \mathrm{D}, \mathrm{D}$, or the $\delta \mathrm{D} / \delta \mathrm{P}$ index) with elements of the insulin resistance syndrome (MAP, glucose uptake, BMI, waist-to-hip ratio, LBM, total body fat, abdominal subcutaneous fat area, visceral fat area, and plasma concentrations of glucose, insulin, HDL-cholesterol, triglycerides and non-esterified fatty acids). Regression coefficients were standardized $(\beta)$, i.e. partial regression coefficients when all variables were expressed in standardized $(z$ score $=[$ value - mean $] /$ standard deviation) form. Interaction terms of these variables with sex were also studied. A stepwise regression model corrected for sex was used to analyse the association between diameter and variables of body composition. Two-sided $p$ less than 0.05 was considered statistically significant. The software used was SPSS for Windows 7.0 (Chicago, Ill., USA).

\section{Results}

In the study group, the men, compared with the women, were on average 5 years older, had a larger femoral and common carotid artery diameter, higher MAP, lower HDL-cholesterol, and lower total and 
Table 2. Associations of arterial distension and stiffness variables with mean arterial pressure and metabolic and body composition parameters in 17 men and 17 women

\begin{tabular}{|c|c|c|c|c|c|c|}
\hline & \multicolumn{3}{|l|}{ Femoral artery } & \multicolumn{3}{|l|}{ Carotid artery } \\
\hline & $\delta \mathrm{D}(\mathrm{mm})$ & $\begin{array}{l}\mathrm{DC} \\
\left(10^{-3} \cdot \mathrm{kPa}^{-1}\right)\end{array}$ & $\begin{array}{l}\mathrm{CC} \\
\left(\mathrm{mm}^{2} \cdot \mathrm{kPa}^{-1}\right)\end{array}$ & $\delta \mathrm{D}(\mathrm{mm})$ & $\begin{array}{l}\mathrm{DC} \\
\left(10^{-3} \cdot \mathrm{kPa}^{-1}\right)\end{array}$ & $\begin{array}{l}\mathrm{CC} \\
\left(\mathrm{mm}^{2} \cdot \mathrm{kPa}^{-1}\right)\end{array}$ \\
\hline Mean arterial pressure $(\mathrm{mmHg})$ & $-0.38(0.049)$ & $-0.45(0.01)$ & $-0.46(0.01)$ & $-0.40(0.03)$ & $-0.53(0.004)$ & $-0.55(0.002)$ \\
\hline $\begin{array}{l}\text { Insulin }(\mathrm{pmol} / \mathrm{l}) \\
\text { Glucose utilization }\left(\mathrm{mg} \cdot \mathrm{kg} \mathrm{LBM}^{-1} \cdot \mathrm{min}^{-1}\right)\end{array}$ & $\begin{array}{r}-0.41(0.02) \\
0.43(0.02)\end{array}$ & $\begin{array}{r}-0.47(0.008) \\
0.53(0.003)\end{array}$ & $\begin{array}{r}-0.37(0.04) \\
0.23(0.22)\end{array}$ & $\begin{array}{l}0.04(0.83) \\
0.17(0.37)\end{array}$ & $\begin{array}{r}-0.07(0.71) \\
0.30(0.11)\end{array}$ & $\begin{array}{l}0.01(0.98) \\
0.13(0.49)\end{array}$ \\
\hline $\begin{array}{l}\text { HDL-cholesterol }(\mathrm{mmol} / \mathrm{l}) \\
\text { Triglyceride }(\mathrm{mmol} / \mathrm{l}) \\
\text { Free fatty acids }(\mathrm{mmol} / \mathrm{l})\end{array}$ & $\begin{array}{r}0.04(0.82) \\
-0.29(0.10) \\
-0.01(0.96)\end{array}$ & $\begin{array}{r}0.02(0.92) \\
-0.25(0.15) \\
-0.09(0.63)\end{array}$ & $\begin{array}{r}0.07(0.70) \\
-0.27(0.12) \\
-0.06(0.75)\end{array}$ & $\begin{array}{r}0.04(0.83) \\
-0.10(0.55) \\
-0.14(0.47)\end{array}$ & $\begin{array}{r}0.15(0.44) \\
-0.22(0.23) \\
-0.26(0.17)\end{array}$ & $\begin{array}{r}-0.03(0.86) \\
0.03(0.86) \\
-0.21(0.25)\end{array}$ \\
\hline $\begin{array}{l}\text { Body mass index }\left(\mathrm{kg} / \mathrm{m}^{2}\right) \\
\text { Waist-to-hip ratio }(\mathrm{m} / \mathrm{m}) \\
\text { Lean body mass }(\mathrm{kg}) \\
\text { Total body fat }(\mathrm{kg}) \\
\text { Abdominal subcutaneous fat area }\left(\mathrm{cm}^{2}\right) \\
\text { Visceral fat area }\left(\mathrm{cm}^{2}\right)\end{array}$ & $\begin{array}{r}-0.01(0.97) \\
-0.14(0.52) \\
0.08(0.75) \\
-0.23(0.32) \\
0.17(0.48) \\
-0.10(0.62)\end{array}$ & $\begin{array}{l}-0.15(0.39) \\
-0.02(0.93) \\
-0.23(0.38) \\
-0.34(0.13) \\
-0.01(0.98) \\
-0.20(0.33)\end{array}$ & $\begin{array}{r}0.18(0.32) \\
-0.06(0.76) \\
0.38(0.14) \\
0.03(0.91) \\
0.47(0.03) \\
0.14(0.59)\end{array}$ & $\begin{array}{r}-0.14(0.42) \\
-0.10(0.61) \\
-0.19(0.45) \\
0.05(0.82) \\
-0.15(0.50) \\
-0.19(0.31)\end{array}$ & $\begin{array}{l}-0.29(0.10) \\
-0.12(0.57) \\
-0.42(0.10) \\
-0.12(0.60) \\
-0.26(0.27) \\
-0.39(0.049)\end{array}$ & $\begin{array}{r}0.00(0.99) \\
0.14(0.48) \\
-0.07(0.77) \\
0.26(0.25) \\
0.11(0.60) \\
0.06(0.76)\end{array}$ \\
\hline
\end{tabular}

Standardized coefficients $(\beta$, corrected for sex) are shown from bivariate regression analyses with sex forced into the model, with $p$-value between parentheses

Table 3. Associations of the arterial diameter and body composition variables in 17 men and 17 women

\begin{tabular}{lll}
\hline & $\begin{array}{l}\text { Femoral artery } \\
\text { diameter }(\mathrm{mm})\end{array}$ & $\begin{array}{l}\text { Carotid artery } \\
\text { diameter }(\mathrm{mm})\end{array}$ \\
\hline Height $(\mathrm{m})$ & $0.47(0.007)$ & $0.30(0.11)$ \\
Weight $(\mathrm{kg})$ & $0.52(0.001)$ & $0.45(0.005)$ \\
Body mass index $\left(\mathrm{kg} / \mathrm{m}^{2}\right)$ & $0.38(0.01)$ & $0.42(0.005)$ \\
Waist-to-hip ratio $(\mathrm{m} / \mathrm{m})$ & $0.00(0.99)$ & $0.31(0.07)$ \\
Lean body mass $(\mathrm{kg})$ & $0.70(0.001)$ & $0.48(0.02)$ \\
Total body fat $(\mathrm{kg})$ & $0.44(0.02)$ & $0.50(0.007)$ \\
Abdominal subcutaneous fat & & \\
area $\left(\mathrm{cm}^{2}\right)$ & $0.41(0.04)$ & $0.44(0.03)$ \\
Visceral fat area $\left(\mathrm{cm}^{2}\right)$ & $0.42(0.01)$ & $0.55(0.001)$ \\
\hline
\end{tabular}

Standardized coefficients $(\beta$, corrected for sex) are shown from bivariate regression analyses with sex forced into the model, with $p$-value between parentheses

abdominal subcutaneous body fat (Table 1). The DC and $\mathrm{CC}$ of the common carotid artery and the femoral artery did not differ between men and women (Table 1). After controlling for age, MAP, HDL-cholesterol, and total and abdominal subcutaneous fat mass, the CCs of the femoral and common carotid arteries were, however, higher in men than in women $(p=0.05$ and $p=0.009)$.

In the femoral artery, DC and CC were inversely related to MAP and insulin concentrations. In addition, DC was positively related to glucose uptake and $\mathrm{CC}$ positively to the abdominal subcutaneous fat area (Table 2). In the common carotid artery, DC and $\mathrm{CC}$ were inversely related to MAP. In addition, DC was inversely related to the visceral fat area (Table 2). Because diameter is a major determinant of DC and CC, we next analysed associations between diameter and variables of body composition. Diame-
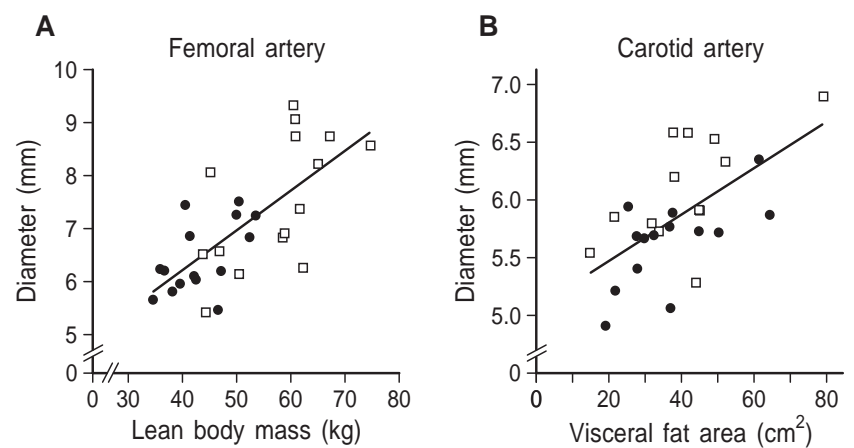

Fig. 1A, B. Scatter plots showing associations of the $\mathbf{A}$ femoral artery diameter and the lean body mass and of the $\mathbf{B}$ carotid artery diameter and the visceral fat area. Standardized bivariate regression coefficients ( $\beta$, corrected for sex) and univariate regression lines in men and women pooled are shown. $\square$ men, women. $\mathbf{A} \beta=0.80, p<0.001 ; \mathbf{B} \beta=0.56, p=0.001$

ter was positively associated with all indices of body size (Table 3). Stepwise linear regression analyses indicated that lean body mass was the only significant determinant of femoral artery diameter, whereas visceral fat area was the only appreciable determinant of common carotid artery diameter (Fig. 1).

We next analysed men and women separately. In women, but not in men, the $\delta \mathrm{D}, \mathrm{DC}$ and $\mathrm{CC}$ of the femoral artery were inversely associated with fasting insulin concentrations and positively with glucose uptake (Fig.2). Interaction analysis showed that only the association between the $\mathrm{CC}$ of the femoral artery and the insulin concentration was stronger in women than in men $(p=0.03)$. In women, the associations of the $\delta \mathrm{D}$ and DC of the femoral artery with glucose uptake were independent of smoking status, age, lipid concentrations and body composition, whereas the association of the $\mathrm{CC}$ of the femoral artery showed a 


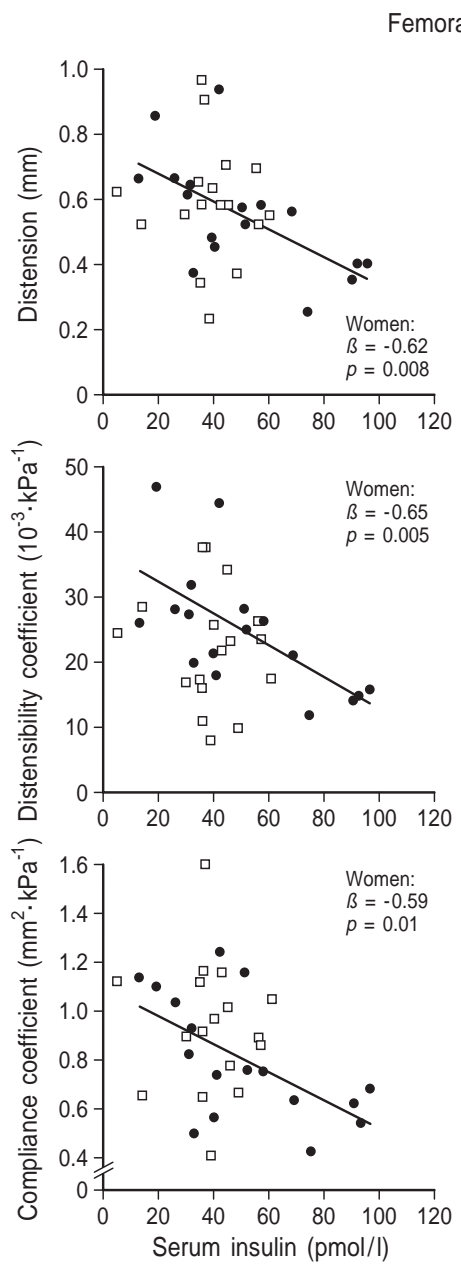

Femoral artery
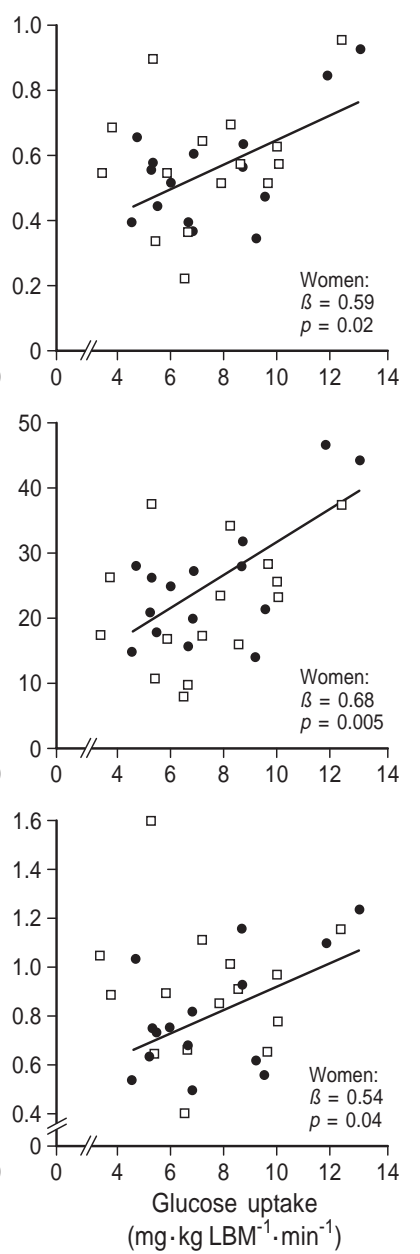

Fig. 2. Scatter plots showing associations of the distension and distensibility and compliance coefficients of the femoral artery with insulin concentrations and glucose uptake. In women, but not in men, these associations were significant. Standardized univariate regression coefficients $(\beta)$ and univariate regression lines are shown only for women. $\square$ men, $\bigcirc$ women

statistical trend $(p<0.10)$ towards independence of lipid concentrations and body composition. To establish this, several multivariate linear regression analyses were done with three independent variables: glucose uptake, MAP and either smoking status (yes or no), age, any metabolic variable (HDL-cholesterol, triglycerides, and non-esterified fatty acids), or any measure of body composition (data not shown). In women, the $\mathrm{CC}$ of the common carotid artery was associated with the total body fat and the abdominal subcutaneous fat area $(\beta=0.56, p=0.03$ and $\beta=0.55, p=0.04)$, which remained significant after correction for MAP and glucose uptake $(\beta=0.67$, $p=0.02$ and $\beta=0.61, p=0.04)$. In men, the $\mathrm{CC}$ of the femoral artery was associated with the abdominal subcutaneous fat area $(\beta=0.64, p=0.02)$, which remained significant after correction for MAP and glucose uptake $(\beta=0.80, p=0.009)$.
As the variables of body composition were strongly associated with the arterial diameter, we next reanalysed the previously mentioned significant associations of DC and CC with variables of body composition and insulin sensitivity with the $\delta \mathrm{D} / \delta \mathrm{P}$ index instead of the DC or CC. The associations of the femoral artery $\delta \mathrm{D} / \delta \mathrm{P}$ index in women with insulin concentrations and insulin sensitivity were significant $(\beta=-0.65, p=0.005$ and $\beta=0.64, p=0.01)$, whereas the associations of the femoral artery and common carotid artery $\delta \mathrm{D} / \delta \mathrm{P}$ index with variables of body composition were not.

\section{Discussion}

This study investigated the associations between the DC and the CC of large arteries with elements of the insulin resistance syndrome in a healthy, non-obese group of young men and women. Our main finding was that, in women, the DC and the $\mathrm{CC}$ of the femoral artery were negatively associated with insulin concentrations and positively with glucose uptake, but not so in men. This association was shown to be independent of the mean arterial pressure, lipid concentrations and body composition. Since this is a crosssectional study, it is not possible to establish a causal relation between insulin resistance and femoral artery stiffness. Taking this into consideration, what might explain this association? Firstly, an underlying disturbance of cellular cation transport could provide a link between arterial stiffness and insulin resistance $[25,39]$. This would increase intracellular sodium and free calcium concentrations and decrease those of intracellular free magnesium, which would promote vasoconstriction and arterial stiffening [25] and could also regulate cellular responsiveness to insulin [39]. This idea is consistent with the finding that insulin sensitivity was associated with arterial stiffness in the muscular femoral artery, but not in the elastic common carotid artery. Secondly, mean blood pressure is a determinant of distensibility and compliance [19, $23,24]$. Further, hypertension is associated with resistance to the action of insulin to stimulate glucose uptake in skeletal muscle [40, 41]. Therefore, it is noteworthy that insulin resistance and femoral artery stiffness were still associated after adjustment for MAP. Thirdly, arterial stiffening could be the result of vessel wall thickening [42]. Common carotid artery wall thickness is positively related to insulin concentrations [43] and an estimate of insulin resistance [44]. Moreover, insulin could induce vascular smooth muscle hypertrophy [45], at least in experimental conditions, and insulin receptors have been found in the arterial wall [46].

A previous study also found stronger correlations between arterial stiffness and fasting insulin concentrations in women than men [20]. In our study, how- 
ever, insulin sensitivity was assessed directly using the euglycaemic hyperinsulinaemic clamp technique. Our findings suggest that the effect of insulin resistance on arterial stiffening is more pronounced in women than in men. In one recent study [13], but not in other studies [11,12], fasting insulin concentrations were associated with coronary heart disease in women, but not in men. Data supporting a sex difference in arterial stiffness are contradictory. Measurement of pulse wave velocity, an estimate of regional arterial stiffness, indicates that arteries in men are stiffer than those in premenopausal women [47, 48] but local artery stiffness of the common carotid artery, measured by ultrasound, was less in men than in women for DC and CC in one study [49], for $\delta \mathrm{D} /$ $\mathrm{D}$, but not for DC, in another study [50] and for CC, but not for DC, in this study. The shorter height in women compared with men is related to earlier wave reflections and, therefore, could relatively increase pulse pressure in women [51]. In addition, a smaller body mass is related to a smaller artery caliber in women than men. A smaller artery diameter together with a larger pulse pressure, could have resulted in a smaller CC in our female subjects. The DC, the intrinsic arterial elastic property that could be most directly linked to cardiovascular risk, did not differ, however, between women and men in our study. Insulin sensitivity also differed between the sexes in previous studies. Women showed a higher glucose uptake rate after adjustment for LBM than men $[52,53]$. The total and relative muscle mass is smaller in women than men and skeletal muscle consumes the majority of glucose under clamp conditions [53]. Since the insulin infusion rates were calculated per kilogram total body mass [53] or per square meter of body surface [52], the sex difference might be ascribed to a relatively larger insulin infusion rate in women than in men. In contrast, we did not find a sex difference in the glucose uptake rate after adjustment for LBM, probably because the insulin infusion rate was also calculated per kilogram LBM.

The arterial diameters of the femoral artery and common carotid artery were associated with most variables of body composition (Table 3 ). On the one hand, the femoral artery diameter was strongly related to the lean body mass, which may be related to the association of LBM with leg musculature. A previous study found the femoral artery diameter to be larger in trained cyclists than in sedentary men [54]. On the other hand, common carotid artery diameter was strongly associated with the visceral fat area. The CC of the femoral artery in men and the $\mathrm{CC}$ of the common carotid artery in women were positively associated with body fat. Moreover, the DC of the common carotid artery in men and women pooled was inversely associated with the visceral fat area. Further analysis showed that all the associations with DC and CC were explained by the associ- ation between body fat and arterial diameter, which is part of the numerator of the $\mathrm{CC}$ and the denominator of the DC. An increased arterial diameter may thus account for the increased arterial compliance that was found in young, obese men compared to lean control subjects [27]. As the muscle and fat mass increases, so will the requirements for blood volume. In these circumstances, a hyperdynamic circulation with reduced systemic vascular resistance can be found $[55,56]$ and an increased arterial diameter and buffering capacity of the arterial system might be required. Alternatively, fat cells could produce vasoactive mediators that influence arterial diameter.

A limitation of our study was that local pulse pressure was not measured. Pulse pressure, however, did not seem to modulate the association between femoral artery stiffness and insulin sensitivity, as illustrated by the association between arterial distension (not corrected for pulse pressure) and insulin sensitivity in women and not in men. Also, diameter rather than pulse pressure appeared to modulate the associations between femoral and common carotid artery stiffness with variables of body composition. Another limitation is that we have no data on wave reflections, which have a strong influence on pulse pressure and, therefore, on arterial distension. The inclusion of only young, non-obese subjects is expected to have limited the influence of wave reflections, which, in youth, return to the left ventricle during diastole rather than systole [2].

The results of our study show that insulin sensitivity was associated with distensibility and compliance of the muscular femoral artery in healthy, young, non-obese women, but not in men. It remains to be established if insulin resistance is causally related to arterial stiffness before diabetes becomes clinically manifest. In addition, arterial compliance was positively associated with fat mass variables, which were mediated by an increased arterial diameter.

Acknowledgements. We are indebted to M. Steyn for the technical assistance and to J.A. J. Megens for assistance in the logistics of this study. Dr. Stehouwer is supported by a Clinical Research Fellowship from the Diabetes Fonds Nederland and the Netherlands Organization for Scientific Research (NWO).

\section{References}

1. Safar ME, Frohlich ED (1995) The arterial system in hypertension: a prospective view. Hypertension 26: 10-14

2. Westerhof N, O'Rourke MF (1995) Haemodynamic basis for the development of left ventricular failure in systolic hypertension and for its logical therapy. J Hypertens 13: 943-952

3. Smulyan H, Safar ME (1997) Systolic blood pressure revisited. J Am Coll Cardiol 29: 1407-1413

4. Boutouyrie P, Laurent S, Girerd X et al. (1995) Common carotid artery stiffness and patterns of left ventricular hy- 
pertrophy in hypertensive patients. Hypertension 25: 651-659

5. Kronmal RA, Smith V, O'Leary DH, Polak JF, Gardin JM, Manolio TA (1996) Carotid artery measures are strongly associated with left ventricular mass in older adults (a report from the Cardiovascular Health Study). Am J Cardiol 77: 628-633

6. Arnold JMO, Marchiori GE, Imrie JR, Burton GL, Pflugfelder PW, Kostuk WJ (1991) Large artery function in patients with chronic heart failure: studies of brachial artery diameter and hemodynamics. Circulation 84: 24182425

7. Hirai T, Sasayama S, Kawasaki T, Yagi S (1989) Stiffness of systemic arteries in patients with myocardial infarction: a non-invasive method to predict severity of coronary atherosclerosis. Circulation 80: 78-86

8. Wada T, Kodaira K, Fujisjiro K et al. (1994) Correlation of ultrasound-measured common carotid artery stiffness with pathological findings. Arterioscler Thromb Vasc Biol 14: 479-482

9. Nakamura T, Tokunaga K, Shimomura I et al. (1994) Contribution of visceral fat accumulation to the development of coronary artery disease in non-obese men. Atherosclerosis 107: 239-246

10. Manson JE, Willett WC, Stampfer MJ et al. (1995) Body weight and mortality among women. N Engl J Med 333: 677-685

11. Modan M, Or J, Karasik A et al. (1991) Hyperinsulinemia, sex, and risk of atherosclerotic cardiovascular disease. Circulation 84: 1165-1175

12. Welborn TA, Knuiman MW, Ward N, Whittall DE (1994) Serum insulin is a risk marker for coronary heart disease mortality in men but not in women. Diabetes Res Clin Prac 26: 51-59

13. Folsom AR, Szklo M, Stevens J, Liao F, Smith R, Eckfeldt JH (1997) A prospective study of coronary heart disease in relation to fasting insulin, glucose, and diabetes: the Atherosclerosis Risk in Communities (ARIC) study. Diabetes Care 20: 935-942

14. Uusitupa M, Siitonen O, Aro A, Pyörälä K (1985) Prevalence of coronary heart disease, left ventricular failure and hypertension in middle-aged, newly diagnosed type 2 (non-insulin-dependent) diabetic subjects. Diabetologia 28: $22-27$

15. Barrett-Connor E, Bush TL (1991) Estrogen and coronary heart disease in women. JAMA 265: 1861-1867

16. Howard G, O'Leary DH, Zaccaro D et al. (1996) Insulin sensitivity and atherosclerosis. Circulation 93: 1809-1817

17. Haffner SM, Lehto S, Rönnemaa T, Pyörälä K, Laakso M (1998) Mortality from coronary heart disease in subjects with type 2 diabetes and in nondiabetic subjects with and without prior myocardial infarction. $\mathrm{N}$ Engl J Med 339: 229-234

18. Neutel JM, Smith DHG, Graettinger WF, Weber MA (1992) Dependency of arterial compliance on circulating neuroendocrine and metabolic factors in normal subjects. Am J Cardiol 69: 1340-1344

19. Kupari M, Hekali P, Keto P, Poutanen V, Tikkanen MJ, Standertskjöld-Nordenstam C (1994) Relation of aortic stiffness to factors modifying the risk of atherosclerosis in healthy people. Arterioscler Thromb Vasc Biol 14: 386394

20. Salomaa V, Riley W, Kark JD, Nardo C, Folsom AR (1995) Non-insulin-dependent diabetes mellitus and fasting glucose and insulin concentrations are associated with arterial stiffness indexes: the ARIC Study. Circulation 91: 14321443
21. Laakso M (1993) How good a marker is insulin level for insulin resistance? Am J Epidemiol 137: 959-965

22. Laws A, Reaven GM (1993) Insulin resistance and risk factors for coronary heart disease. Balliere's Clin Endocrinol Metab 7: 1063-1078

23. Cameron JD, Jennings GL, Dart AM (1995) The relationship between arterial compliance, age, blood pressure and serum lipid levels. J Hypertens 13: 1718-1723

24. Relf IRN, Lo CS, Myers KA, Wahlqvist ML (1986) Risk factors for changes in aorto-iliac arterial compliance in healthy men. Arteriosclerosis 6: 105-108

25. Resnick LM, Militianu D, Cunnings AJ, Pipe JG, Evelhoch JL, Soulen RL (1997) Direct magnetic resonance determination of aortic distensibility in essential hypertension: relation to age, abdominal visceral fat, and in situ intracellular free magnesium. Hypertension 30: 654-659

26. Wahlqvist ML, Lo CS, Myers KA, Simpson RW, Simpson JM (1988) Putative determinants of arterial wall compliance in NIDDM. Diabetes Care 11: 787-790

27. Mangoni AA, Giannattasio C, Brunani A et al. (1995) Radial artery compliance in young, obese, normotensive subjects. Hypertension 26: 984-988

28. DeFronzo RA, Tobin JD, Andres R (1979) Glucose clamp technique: a method for quantifying insulin secretion and resistance. Am J Physiol 237:E214-E223

29. Hoeks APG, Brands PJ, Smeets FAM, Reneman RS (1990) Assessment of the distensibility of superficial arteries. U1trasound Med Biol 16: 121-128

30. Kool MJF, Van Merode T, Reneman RS, Hoeks APG, Struyker Boudier HAJ, Van Bortel LMAB (1994) Evaluation of reproducibility of a vessel wall movement detector system for assessment of large artery properties. Cardiovasc Res 28: 614-619

31. Peterson LH, Jensen RE, Parnell J (1960) Mechanical properties of arteries in vivo. Circ Res 8: 622-639

32. Dobrin PB (1978) Mechanical properties of arteries. Physiol Rev 58: 397-460

33. Lambert J, Smulders RA, Aarsen M, Donker AJM, Stehouwer CDA (1998) Carotid artery stiffness is increased in microalbuminuric IDDM patients. Diabetes Care 21: 99-103

34. Renemans RS, Van Merode T, Brands PJ, Hoeks APG (1992) Inhomogeneties in arterial wall properties under normal and pathological conditions. J Hypertens 10 [Suppl 6]:S35-S39

35. Segal KR, Van Loan M, Fitzgerald PI, Hodgdon JA, Van Itallie TB (1988) Lean body mass estimation by bioelectrical impedance analysis: a four-site cross-validation study. Am J Clin Nutr 47: 7-14

36. Björntorp P (1990) "Portal" adipose tissue as a generator of risk factors for cardiovascular disease and diabetes. Arteriosclerosis 10: 493-496

37. Després J, Moorjani S, Lupien PJ, Tremblay A, Nadeau A, Bouchard C (1990) Regional distribution of body fat, plasma lipoproteins, and cardiovascular disease. Arteriosclerosis 10: 497-511

38. Elbers JMH, Haumann G, Asscheman H, Seidell JC, Gooren LJG (1997) Reproducibility of fat area measurements in young, non-obese subjects by computerized analysis of magnetic resonance images. Int J Obes 21: 1121-1129

39. Barbagallo M, Gupta RK, Bardicef O, Bardicef M, Resnick LM (1997) Altered ionic effects of insulin in hypertension: role of basal ion levels in determining cellular responsiveness. J Clin Endocrinol Metab 82: 1761-1765

40. Natali A, Santoro D, Palombo C, Cerri M, Ghione S, Ferrannini $E$ (1991) Impaired insulin action on skeletal muscle metabolism in essential hypertension. Hypertension 17: 170-178 
41. Capaldo B, Lembo G, Napoli R et al. (1991) Skeletal muscle is a primary site of insulin resistance in essential hypertension. Metabolism 40: 1320-1322

42. Christensen T, Neubauer B (1988) Increased arterial wall stiffness and thickness in medium-sized arteries in patients with insulin-dependent diabetes mellitus. Acta Radiol 29: 299-302

43. Folsom AR, Eckfeldt JH, Weitzman S et al. (1994) Relation of carotid artery wall thickness to diabetes mellitus, fasting glucose and insulin, body size, and physical activity. Stroke 25: 66-73

44. Bonora E, Tessari R, Micciolo R et al. (1997) Intimal-medial thickness of the carotid artery in nondiabetic and NIDDM patients: relationship with insulin resistance. Diabetes Care 20: 627-631

45. Pfeiffle B, Ditschuneit H (1981) Effect of insulin on growth of cultured human arterial smooth muscle cells. Diabetologia 20: $155-158$

46. King GL, Goodman AD, Buzney S, Moses A, Kahn CR (1985) Receptors and growth-promoting effects of insulin and insulin-like growth factor on cells from bovine retinal capillaries and aorta. J Clin Invest 75: 1028-1036

47. Lehmann ED, Parker JR, Hopkins KD et al. (1993) Validation and reproducibility of pressure-corrected aortic distensibility measurements using pulse-wave-velocity. J Biomed Eng 15: 221-228

48. London GM, Guerin AP, Pannier B, Marchais SJ, Stimpel M (1995) Influence of sex on arterial hemodynamics and blood pressure: role of body height. Hypertension 26: 514-519

49. Van Merode T, Hick PJJ, Hoeks APG, Smeets FAM, Reneman RS (1988) Differences in carotid artery wall properties between presumed-healthy men and women. Ultrasound Med Biol 14: 571-574

50. Riley WA, Barnes RW, Schey HM (1984) An approach to the non-invasive periodic assessment of arterial elasticity in the young. Prev Med 13: 169-184

51. London GM, Guerin AP, Pannier BM, Marchais SJ, Metivier F (1992). Body height as a determinant of carotid pulse contour in humans. J Hypertens 1 [Suppl 6]:S93-S96

52. Yki-Järvinen H (1984) Sex and insulin sensitivity. Metabolism 33: 1011-1015

53. Nuutila P, Knuuti MJ, Mäki M et al. (1995) Gender and insulin sensitivity in the heart and in skeletal muscles: studies using positron emission tomography. Diabetes 44: 31-36

54. Kool MJ, Struijker-Boudier HA, Wijnen JA, Hoeks AP, Van Bortel LM (1992) Effects of diurnal variability and exercise training on properties of large arteries. J Hypertens 10 [Suppl]:S49-S52

55. Messerli FH, Christie B, De Carvalho JGR et al. (1981) Obesity and essential hypertension: hemodynamics, intravascular volume, sodium excretion, and plasma renin activity. Arch Intern Med 141: 81-85

56. De Divitis O, Fazio S, Petitto M, Maddalena G, Contaldo F, Mancini M (1981) Obesity and cardiac function. Circulation 64: 477-482 